\title{
THE CHARACTERISTICS AND ANTIOXIDANT ACTIVITIES OF CHABA MAPLE (HIBISCUS ACETOSELLA) HOMEMADE JAM
}

\author{
SURADWADEE THUNGMUNGMEE*, NAKUNTWALAI WISIDSRI, WARACHATE KHOBJAI, \\ THISAKORN DUMRONGPHUTTIDECHA, KHEMJIRA JAMKOM, SURACHAI TECHAEOI
}

Department of Thai Traditional Medicine, Rajamangala University of Technology Thanyaburi, Pathum Thani, Thailand. Email: suradwadee_t@rmutt.ac.th

Received: 12 January 2019, Revised and Accepted: 19 July 2019

ABSTRACT

Objective: This study aimed to characterize physicochemical and chemical characteristics of Chaba maple (Hibiscus acetosella) homemade jam (CHJ) and determine its autoxidation ability.

Methods: The physicochemical and chemical characteristics of $\mathrm{CHJ}$ were investigated. The color, viscosity, and pH were observed as physicochemical data while chemical properties were obtained from sugar content and total polyphenol content (TPC), determined using high-performance liquid chromatography refractometer and Folin-Ciocalteu assay, respectively. The antioxidant activities of $\mathrm{CHJ}$ were identified using 1,1-diphenyl-2picrylhydrazyl (DPPH) radical scavenging, ferric reducing antioxidant power (FRAP), and nitric oxide (NO) radical scavenging ability methods.

Results: The color and viscosity of $\mathrm{CHJ}$ were purple-red and $34,483.33 \pm 152.75 \mathrm{cP}$, respectively. The pH was at 3.78 . The total sugar was not detected in $\mathrm{CHJ}$. The TPC of $\mathrm{CHJ}$ showed the highest (47.18 $\pm 1.80 \mathrm{mg}$ gallic acid equivalent [GAE]/g of jam) followed by Streamline (SL) (23.66 $\pm 0.32 \mathrm{mg}$ GAE/g of jam), Doikham (DK) (21.99 $\pm 0.50 \mathrm{mg} \mathrm{GAE} / \mathrm{g}$ of jam), and Best food (BF) (9.75 $\pm 0.38 \mathrm{mg}$ GAE/g of jam), respectively. Antioxidant activities of $\mathrm{CHJ}$ with \%1,1-diphenyl-2-picrylhydrazyl (DPPH) radical scavenging of $100.00 \pm 1.39 \%$ and FRAP value of $1690.70 \pm 8.26$ uM. Both of activities exhibited the highest activity and significantly different when compared with other jams. The \%NO scavenging activity of CHJ and SL was $72.43 \pm 1.93 \%$ and $73.82 \pm 1.66 \%$, respectively, which higher than DK and BF.

Conclusion: This study shows good in both physicochemical and chemical characteristics of CHJ. The CHJ presents the highest TPC as well as antioxidant activities. Thus, a homemade jam of Chaba maple may be considered as a good source of antioxidants and functional foods.

Keywords: Chaba maple (Hibiscus acetosella), Homemade jam, Antioxidation, Total polyphenol content.

(C) 2019 The Authors. Published by Innovare Academic Sciences Pvt Ltd. This is an open access article under the CC BY license (http://creativecommons. org/licenses/by/4. 0/) DOI: http://dx.doi.org/10.22159/ijap.2019.v11s5.T0048

\section{INTRODUCTION}

Jam is one of the most popular products in the market made from several fruits such as apricot, pineapple, grape, strawberry, blueberry, cranberries, and black currant for preserving the food. There are many parts of plants which have been used to prepare a jam and the different part of plant can provide a varied bioactive compounds, phenolics, flavonoids, and anthocyanins [1]. Typically, jam is composed of at least $40 \%$ of fruit mixed with sugar and gelling agent, using by thermal processing [2]. Low sugar and low-calorie fruit jams have increased in the market for protecting obesity and diabetes [3]. Therefore, sweeteners as sorbitol, xylitol, steviol glycosides, and erythritol have been replaced.

Chaba maple (Hibiscus acetosella) is the plant found in Pathum Thani, Saraburi, Nonthaburi, and Nakhon Nayok, Thailand. Chaba maple is in Malvaceae family and well known in African rosemallow, false roselle, maroon mallow, cranberry hibiscus, or red-leaved hibiscus [4]. This plant is a perennial subshrub and ornamental plant as well as fresh food. All parts of this plant are purple-red color. In previous studied, flowers and leaves of Hibiscus species and Chaba maple showed biological activities including antioxidant, antityrosinase, and antibacterial activities [5-9]. All of these activities were obtained from phenolic compounds such as anthocyanins (i.e., cyanidin, delphinidin, and malvidin), flavonols (quercetin, kaempferol, and myricetin) in flowers, and caffeoyl-hydroxycitric acid and neochlorogenic acid in leaves. These compounds show a wide range of antioxidant activities which prevent to degenerate of neuronal disorders, cardiovascular disease, cancer, and diabetes.
In this study, the attractive purple-red color of Chaba maple parts was made to jam. To ensure the quality as antioxidation of Chaba maple jam, the total polyphenol content (TPC) and antioxidant activities of Chaba maple homemade jam $(\mathrm{CHJ})$ were evaluated. Moreover, these results were compared with three commercial products.

\section{METHODS}

Plant material

The fresh flowers and leaves of Chaba maple were collected from Pathum Thani, Thailand, on September 2018. The petals and leaves were used for $\mathrm{CHJ}$ preparation.

\section{Chemicals}

Folin-Ciocalteu's phenol reagent, gallic acid, L-ascorbic acid, aluminum chloride, DPPH, and sodium nitroprusside (SNP) were purchased from Sigma Chemical Co. (St. Louis, MO, USA). Griess Reagent Kit was obtained from Promega Corporation (Promega, State, USA). All of chemicals in the study were analytical grade. The available jams in the market were purchased from Tesco Lotus supermarket (Pathum Thani, Thailand) including, Best food (BF), Doikham (DK), and Streamline (SL) jam.

\section{CHJ preparation}

The jam formula was $44.44 \%$ of petals, $35.56 \%$ of leaf juice (fresh leaves:water, $1: 4), 17.78 \%$ of erythritol, $1.78 \%$ of lemon juice, and $0.44 \%$ of salt. First, the leaves were boiled for $15 \mathrm{~min}$ and filtered. The filtrated solution was then used and heated to $70-80^{\circ} \mathrm{C}$ after that the petals were added and allowed to boil for $10 \mathrm{~min}$. The lemon juice, 
salt, and erythritol were added, respectively, and mixed together. The mixture was mixing at $60^{\circ} \mathrm{C}$ for $1 \mathrm{~h}$ and allowed to cool down at room temperature. This jam was stored under $2-4^{\circ} \mathrm{C}$ until analysis.

\section{Characterization of $\mathrm{CHJ}$}

Color

The color of $\mathrm{CHJ}$ was evaluated by organoleptic and instrument. For the instrument, the measurement based on $\mathrm{CIE}_{\mathrm{L}^{*} \mathrm{a}^{*} \mathrm{~b}^{*}}$ system of the color parameter using spectrophotometer (ColorQuest XE, HunterLab, USA). The $\mathrm{L}^{*}$ (lightness), a* (greenness [-] to redness [+]), and $\mathrm{b}^{*}$ (blueness [-] to yellowness [+]) were measured.

\section{Viscosity}

The viscosity of $\mathrm{CHJ}$ was measured using a Brookfield Viscometer (DV2T, Brookfield Engineering Laboratories, USA) at $25^{\circ} \mathrm{C}$. Viscometer was adjusted to zero and the spindle LV6 was set in the instrument.

\section{pH measurement}

The sample of $\mathrm{CHJ}$ was blended with deionized water (1:9 jam:water, w/w) for 1 min using vortex mixer (WiseMix ${ }^{\circledR}$, Korea) and then was filtrated before measuring. The $\mathrm{pH}$ of filtered solution was determined using a pH meter (SP-2100, Suntex, Taiwan)

\section{Total sugar}

The total sugars were analyzed using high-performance liquid chromatography (HPLC) with refractive index detector. One gram of $\mathrm{CHJ}$ was dissolved in $25 \mathrm{ml}$ acetonitrile:water (50:50 v:v). This solution was then centrifuged for 10 minutes at $8000 \mathrm{rpm}$. The supernatant was filtered using 0.45 nylon filter. Separation were carried out on an aminobonded column with a mobile phase of acetonitrile:water:triethylamine (75:25:0.2) and sugar content were determined by Refractive Index Detector against the standard solution $(0.1,0.2,0.5,0.8$ and $1.0 \mathrm{ppm}$ of fructose, glucose, sucrose, maltose, and lactose). The column and the refractive index detector were maintained at $30^{\circ} \mathrm{C}$. The injection volume was $10 \mu \mathrm{l}$ and flow rate was $1.5 \mathrm{ml} / \mathrm{min}$.

\section{Sample preparation for phytochemical analysis}

The $\mathrm{CHJ}$ and commercial jams, i.e., BF, DK, and SL were extracted with water solvent and assisted by ultrasonic method. The $250 \mathrm{mg}$ of jams were mixed with $5 \mathrm{ml}$ distilled water and immersed in a temperature controlled ultrasonic bath (Elmasonic Easy $60 \mathrm{H}$, Germany) at $30^{\circ} \mathrm{C}$ for $5 \mathrm{~min}$. Then, the extracts were centrifuge (Universal $320 \mathrm{R}$, Germany) at $9000 \mathrm{rpm}$ for $10 \mathrm{~min}$. The supernatants were collected to obtain the extract samples and kept at $-20^{\circ} \mathrm{C}$ before analysis.

\section{Determination of TPC}

The amount of TPC of CHJ, BF, DK, and SL was determined by Folin-Ciocalteu assay which modified from Kamtekar et al. [10]. Briefly, $10 \mu \mathrm{l}$ of $10 \mathrm{mg} / \mathrm{ml}$ extract samples were filled into 96-well microplate and then $100 \mu \mathrm{l}$ of 1:10 diluted Folin-Ciocalteu reagent was added. After incubation at room temperature for $7 \mathrm{~min}, 80 \mu \mathrm{l}$ of $7 \% \mathrm{w} / \mathrm{v}$ of sodium carbonate was added. After storing in dark room temperature for $2 \mathrm{~h}$, the mixture was recorded under microplate reader (Glomax-Multi Detection System, USA) at $750 \mathrm{~nm}$. TPC was estimated from a calibration curve of standard gallic acid solution. All extracts were measured in 3 times and the results were expressed as milligram gallic acid equivalent (GAE)/g of jam.

\section{Determination of antioxidant activities $D P P H$ radical scavenging assay}

Free radical scavenging activity of jams was measured by 1,1-diphenyl2-picrylhydrazyl (DPPH) according to a modified method of Lee et al. In brief, $75 \mu \mathrm{l}$ of jam solutions was mixed with $150 \mu \mathrm{l}$ of $0.2 \mathrm{mM}$ DPPH the jam solutions. The reaction of mixtures was carried out at room temperature for $30 \mathrm{~min}$. After incubation, the mixtures were measured at $517 \mathrm{~nm}$ using microplate reader (Glomax-Multi Detection System, USA). L-ascorbic acid was used as a positive control and water was used as a blank. The experiment was done in triplicate. The antioxidant capacities of jams were expressed as \% DPPH radical scavenging.

$\%$ DPPH radical scavenging $=\left[\left(A_{517 \text { blank }}-A_{517 \text { sample }}\right) / A_{517 \text { blank }}\right] \times 100$

Where, $A_{517 \text { blank }}$ is absorbance of negative control (water) and $A_{517 \text { sample }}$ is absorbance of jam solution.

\section{Ferric reducing antioxidant power (FRAP) assay}

FRAP assay was measured according to Abolhasani et al. [11] method with some modifications, based on the reduction of $\mathrm{Fe}^{3+}$-TPTZ to a bluecolored $\mathrm{Fe}^{2+}$-TPTZ. First, the FRAP reagent was prepared by mixing of $10 \mathrm{ml}$ of $0.3 \mathrm{M}$ sodium acetate buffer solution, $1.0 \mathrm{ml}$ of $10 \mathrm{mM} \mathrm{TPTZ}$, and $1.0 \mathrm{ml}$ of $20 \mathrm{mM} \mathrm{FeCl}_{3}$ and then incubated at $37^{\circ} \mathrm{C}$ for $4 \mathrm{~min}$. The $150 \mu \mathrm{l}$ of FRAP reagent was mixed with $20 \mu \mathrm{l}$ of each jam solution $(50 \mathrm{mg} / \mathrm{ml})$ and incubated at $37^{\circ} \mathrm{C}$ for $30 \mathrm{~min}$. The absorbance of the reaction mixture was measured at $600 \mathrm{~nm}$ using a microplate reader (Glomax-Multi Detection System, USA). The calibration curve was prepared using standard $1 \mathrm{mM}$ $\mathrm{FeSO}_{4}$ solution. The FRAP value of the sample was expressed as $\mu \mathrm{M}$.

\section{Nitric oxide (NO) radical scavenging assay}

NO donor was generated from SNP interacts with oxygen. This assay is modified from Sasikumar and Kalaisezhiyen [12]. Exactly, $10 \mathrm{mM}$ of SNP in a phosphate-buffered solution ( $\mathrm{pH}$ 7.4) was incubated with $1 \mathrm{ml}$ of jam solution at $25^{\circ} \mathrm{C}$ for $3 \mathrm{~h}$. A $100 \mu \mathrm{l}$ of the testing solution was withdrawn to react with a Griess Reagent Kit, whereby the solution was reacted with $20 \mu \mathrm{l}$ sulfanilamide for $10 \mathrm{~min}$ and then $20 \mu \mathrm{l} \mathrm{N}$-(1-naphthyl) ethylenediamine dihydrochloride for another $10 \mathrm{~min}$. The reaction mixture absorbance was measured at $560 \mathrm{~nm}$ and the NO concentrations were determined as the nitrite $\left(\mathrm{NO}^{2-}\right)$ concentrations from the standard curve of a standard nitrite solution. Distill water and L-ascorbic acid were used as the negative and positive controls, respectively. Percentage inhibition of the nitrite ions generated is observed as NO scavenging capacity of jam solution following below equation.

$\%$ NO radical scavenging $=\left[\left(A_{560 \text { blank }}-A_{560 \text { sample }}\right) / A_{560 \text { blank }}\right] \times 100$

Where, $A_{560 \text { blank }}$ is absorbance of negative control (water) and $A_{560 \text { sample }}$ is absorbance of jam solution.

\section{Statistical analysis}

Data are reported as the mean \pm standard deviation of triplicated experiments. TPC and antioxidant activities were analyzed by one-way analysis of variance followed by Tukey's (post hoc) using the SPSS 22.0 software. Significance was accepted at $\mathrm{p}<0.05$.

\section{RESULTS AND DISCUSSION}

\section{Characteristics of $\mathrm{CH}$}

The characteristic of $\mathrm{CHJ}$ is shown in Fig. 1. For physical characteristics, the color of jam is purple-red, similar to their petal and leave's color. For the color analysis, $\mathrm{CHJ}$ showed dark purple-red by visual observation and showed low $\mathrm{L}^{*}$ value $(1.90 \pm 0.01)$ that represented dark color while $\mathrm{a}^{*}$ showed high value $(13.36 \pm 0.08)$ with redness (dark red color) and $\mathrm{b}^{*}$ showed quite blue color (Table 1). The $\mathrm{pH}$ of $\mathrm{CHJ}$ was at 3.78. The $\mathrm{CHJ}$

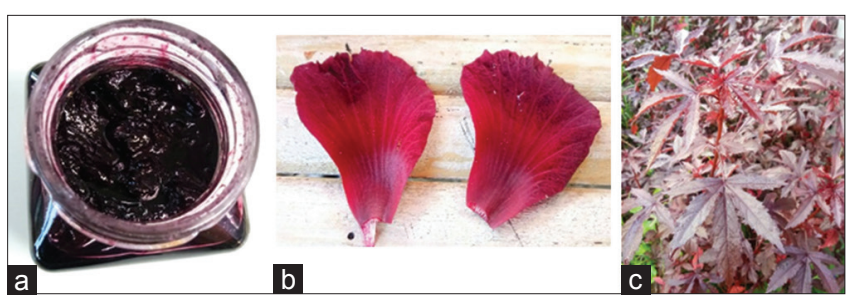

Fig. 1: The color of Chaba maple homemade jam by organoleptic observation (a), the petals (b), and leaves (c) of Chaba maple 
Table 1: Determination of physicochemical and chemical characteristics of Chaba maple homemade jam

\begin{tabular}{|c|c|c|c|c|c|}
\hline \multicolumn{3}{|l|}{ Color $^{\mathrm{a}}$} & \multirow[t]{2}{*}{ pH } & \multirow[t]{2}{*}{ Viscosity $(c P)^{a}$} & \multirow[t]{2}{*}{ Total sugar $(\mathrm{g} / \mathbf{1 0 0} \mathrm{g})$} \\
\hline $\mathbf{L}^{*}$ & $\mathbf{a}^{*}$ & $\mathbf{b}^{*}$ & & & \\
\hline $1.90 \pm 0.01$ & $13.36 \pm 0.08$ & $3.27 \pm 0.02$ & 3.78 & $34,483.33 \pm 152.75$ & Not detected \\
\hline
\end{tabular}

Table 2: Determination of TPC and antioxidant activities in various jams

\begin{tabular}{|c|c|c|c|c|}
\hline \multirow[t]{2}{*}{ Test sample $^{a}$} & \multirow[t]{2}{*}{ TPC (mg GAE/g of jam) ${ }^{b}$} & \multicolumn{3}{|l|}{ Antioxidant activities $^{\mathrm{b}}$} \\
\hline & & $\%$ radical scavenging & FRAP values $(\mu \mathrm{M})$ & $\%$ NO radical scavenging \\
\hline $\mathrm{BF}$ & $9.75 \pm 0.38^{c}$ & $70.40 \pm 2.79^{c}$ & $540.58 \pm 5.05^{c}$ & $17.58 \pm 1.72^{\mathrm{c}}$ \\
\hline DK & $21.99 \pm 0.50^{c}$ & $97.01 \pm 0.39^{c}$ & $1169.34 \pm 20.55^{c}$ & $63.89 \pm 1.27^{c}$ \\
\hline SL & $23.66 \pm 0.32^{c}$ & $95.64 \pm 1.82^{c}$ & $1179.03 \pm 6.52^{c}$ & $73.82 \pm 1.66$ \\
\hline $\mathrm{CHJ}$ & $47.18 \pm 1.80$ & $100.00 \pm 1.39$ & $1690.70 \pm 8.26$ & $72.43 \pm 1.93$ \\
\hline 1 mM L-ascorbic acid & - & - & $1706.36 \pm 0.002$ & - \\
\hline $0.0625 \mathrm{mg} / \mathrm{ml} \mathrm{L}$-ascorbic acid & - & - & - & $87.72 \pm 0.79$ \\
\hline
\end{tabular}

${ }^{a}$ Test sample: BF: Best food, DK: Doikham, SL: Streamline, CHJ: Chaba maple homemade jam. ${ }^{b}$ Values are expressed as means \pm SD (n=3). ${ }^{c} p<0.05$ is significantly differences when compared with CHJ. TPC: Total polyphenol content

showed high viscosity $(34,483.33 \pm 152.75 \mathrm{cP})$ due to high quantity of petals. In the formulation, erythritol was chosen to use as sweetening agent which tastes like sugar, contains almost zero calories. Then, the result of total sugar by HPLC analysis represented no sugar including fructose, glucose, sucrose, maltose, and lactose. Therefore, $\mathrm{CHJ}$ may be beneficial for patients who want to control sugar or sugar control people.

TPC

It is known that edible plants contain huge phytochemicals that could be useful for disease protecting and lowering the risk of various cancers as well as prevention of free radical inducing properties in inflammation-related disorders and cardiovascular diseases [13]. Several plants contain phenolic and flavonoid compounds. A literature review, phenolic compounds in Chaba maple were caffeic acid, gallic acid, gallocatechin, coumaric acid, 3,4-dihydroxybenzoic acid, caffeoylhydroxycitric acid, chlorogenic acid, quercetin-3-galactoside in leaves, and cyanidin and myricetin in flowers $[5,6,14,7]$. The TPC of $\mathrm{CHJ}$ was determined compare to three commercial products, BF, DK, and SL. All of them contain the fruits, for example, mulberry, strawberry, and cranberry that contain phenolic compounds such as phenolic acids, flavonoids-flavonols, anthocyanins, tannins, and ascorbic acid [15]. Results are summarized in Table 2. The TPC of $\mathrm{CHJ}$ showed the highest value for $47.18 \pm 1.80 \mathrm{mg} \mathrm{GAE} / \mathrm{g}$ of jam while BF showed the lowest. DK and SL showed TPC value 21.99 and $23.66 \mathrm{mg}$ GAE/g of jam, respectively, which had no significantly difference. As the lowest of TPC, BF is $23.66 \pm 0.32 \mathrm{mg} \mathrm{GAE} / \mathrm{g}$ of jam. Comparing the different jam, TPC represented the quantity genuine plant and in product. The CHJ contains $44.44 \%$ Chaba maple petals and $35.56 \%$ Chaba maple leaves juice while DK, SL, and BF contain $72 \%$ mulberry, $50 \%$ blackcurrant, and $10 \%$ mixed berries ( $6 \%$ strawberry and $4 \%$ blueberry), respectively. From our studied, total phenolic content, total flavonoid content, and anthocyanin were found in the leaves and flowers of Chaba maple. Therefore, $\mathrm{CHJ}$ showed good source of total phenolic compounds.

\section{Antioxidant activities}

Phenolic compounds are primary antioxidant that acts as free radical scavenger [16]. They can donate hydrogen atom scavenging free radicals and reducing power and then produce antioxidant radicals which are stable compounds. Antioxidant activities of $\mathrm{CHJ}$ and commercial jams were evaluated by the radical scavenging activity using DPPH and NO assay and the capacity of reducing power of jams using FRAP assay. For DPPH assay, CHJ presented the highest percentage radical scavenging properties with $100.00 \pm 1.39$ followed by DK, SL, and $\mathrm{BF}$, respectively (Table 2). As for NO radical scavenging activity, $\mathrm{CHJ}$ showed reduction of NO generation from SNP by $72.43 \pm 1.93 \%$ as well as SL $(73.82 \pm 1.66 \%)$ and followed by DK and BF, respectively. When compared to other jams, $\mathrm{CHJ}$ exhibited highest reducing power ability that caused the reduction of $\mathrm{Fe} 3+/$ ferricyanide complex to the ferrous form. From previous studied, the leaves and flowers of Chaba maple in various extraction displayed total phenolic and flavonoids contents and antioxidant activities as well. Vilela et al. (2018) revealed that phenolic compounds in Chaba maple leaves could provide protective effects against genotoxicity and mutagenicity induced by alkylating agents which important role in protection against DNA damage in mice [14]. The methanolic extract of Chaba maple leaves, especially 2-0-transcaffeoyl-hydroxycitric acid and major phenolic acid, showed antioxidant and anti-inflammatory activities by inhibiting intracellular reactive oxygen species (ROS) production by HL60 cells and extracellular ROS production by neutrophil polymorphonucleocytes and on the activity of pro-inflammatory enzyme myeloperoxidase [7]. The polyphenols and flavonoids in young Chaba maple leaves extract showed inhibit ROS produced by activated neutrophils [5]. From the previous research supported that the TPCs were well correlation between phenolic compounds and their antioxidant activities. It is noted that polyphenol compounds of jams were contributing to radical scavenging activity. Therefore, this study presents antioxidant activity of a homemade jam through difference mechanisms that may lower the risk of health disorders such as cancer, heart disease, and diabetes.

\section{CONCLUSION}

CHJ shows a good physical and chemical properties. This jam provides a good source of antioxidant similar with TPC which a choice in healthcare food and functional food. To fulfill the jam product development, the forthcoming research in nutrition analysis, microbiological activity, and safety need to be evaluated.

\section{ACKNOWLEDGMENT}

This work was supported by Thai Traditional Medicine College, Rajamangala University of Technology Thanyaburi.

\section{REFERENCES}

1. Lee DJ, Lee H, Lee SH, Lee CY, Kim DO. Effects of jam processing on anthocyanins and antioxidant capacities of Rubus coreanus Miquel berry. Food Sci Biotechnol 2013;22:1607-12.

2. Basu S, Shivhare US. Rheological, textural, micro-structural and sensory properties of mango jam. J Food Eng 2010;100:357-65.

3. Bana's A, Korus A, Korus JB. Texture, color, and sensory features of low-sugar gooseberry jams enriched with plant ingredients with prohealth properties. J Food Qual 2018;2018:1-12.

4. Mahr S, editor. In: Hibiscus acetosella. Wisconsin Master Gardener. Wisconsin: University of Wisconsin; 2008. 
5. Tsumbu CN, Deby-Dupont G, Tits M, Angenot L, Frederich M, Kohnen S, et al. Polyphenol content and modulatory activities of some tropical dietary plant extracts on the oxidant activities of neutrophils and myeloperoxidase. Int J Mol Sci 2012;13:628-50.

6. Puckhaber LS, Stipanovic RD, Bost GA. Analyses for flavonoid aglycones in fresh and preserved Hibiscus flowers. In: Janick J, Whipkey A, editors. Trends in New Crops and New Uses. Alexandria: ASHS Press; 2002. p. 556-63.

7. Kapepula PM, Kabamba Ngombe N, Tshisekedi Tshibangu P, Tsumbu C, Franck T, Mouithys-Mickalad A, et al. Comparison of metabolic profiles and bioactivities of the leaves of three edible congolese hibiscus species. Nat Prod Res 2017;31:2885-92.

8. Brain A, John M. Phenolic content and antioxidant activity of selectd Ugandan traditional medicinal foods. Afr J Food Sci 2014;8:427-34.

9. Wong SK, Lim YY, Chan EC. Evaluation of antioxidant, anti-tyrosinase and antibacterial activities of selected Hibiscus species. Ethnobot Leafl 2010;14:781-96.

10. Kamtekar S, Keer V, Patil V. Estimation of phenolic content, flavonoid content, antioxidant and alpha amylase inhibitory activity of marketed polyherbal formulation. J Appl Pharm Sci 2014;4:61-5.
11. Abolhasani A, Barzegar M, Sahari MA. Effect of gamma irradiation on the extraction yield, antioxidant, and antityrosinase activities of pistachio green hull extract. Radiat Phys Chem 2018;144:373-8

12. Sasikumar V, Kalaisezhiyen P. Evaluation of free radical scavenging activity of various leaf extracts from Kedrostis foetidissima (Jacq.) Cogn. Biochem Anal Biochem 2014;3:1-7.

13. Esmaeili MA, Sonboli A. Antioxidant, free radical scavenging activities of Salvia brachyantha and its protective effect against oxidative cardiac cell injury. Food Chem Toxicol 2010;48:846-53.

14. Vilela TC, Leffa DD, Damiani AP, Damazio DDC, Manenti AV, Carvalho TJG, et al. Hibiscus acetosella extract protects against alkylating agent-induced DNA damage in mice. An Acad Bras Cienc 2018;90:3165-74.

15. Skrovankova S, Sumczynski D, Mlcek J, Jurikova T, Sochor J. Bioactive compounds and antioxidant activity in different types of berries. Int $\mathrm{J}$ Mol Sci 2015;16:24673-706.

16. Shahidi F, Ambigaipalan P. Phenolics and polyphenolics in foods, beverages and spices: Antioxidant activity and health effects a review. J Funct Foods 2015;18:820-97. 